7. Reprod. Fertil. (1962) 4, 103-110

\title{
IMMUNE FLUORESCENCE TECHNIQUE AND THE ISOANTIGENICITY OF MAMMALIAN SPERMATOZOA
}

\author{
J. SWANSON BECK, ${ }^{*}$ R. G. EDWARDS AND M. R. YOUNG
}

Divisions of Immunology, Experimental Biology and Biophysics, National Institute for Medical Research, Mill Hill, London N.W.7

(Received 6th December 1961)

Summary. The immune fluorescence technique has been used to study reactions between serum and spermatozoa from several species of mammals.

Normal serum from adult guinea-pigs, rabbits, mice and men stained the acrosomes of homologous and heterologous spermatozoa, staining being most intense with rabbit and guinea-pig spermatozoa. Staining was weak with sera from rabbits up to 3 weeks of age, and could be removed by heating or Seitz-filtering the sera. Sera from immature guinea-pigs likewise lost most of their staining capacity on heating. Differences in the intensity of staining appeared to be determined chiefly by the species of spermatozoa rather than by the species of serum.

Serum from guinea-pigs immunized with homologous spermatozoa stained the surface of homologous sperm tails, in addition to the acrosomal staining. A slight cross-reaction probably occurred between this serum and the tails of hamster spermatozoa, but not with spermatozoa from other species. Immunization of rabbits with homologous spermatozoa failed to produce any tail staining.

The two reactions between serum and spermatozoa, i.e. with acrosomes and tails, are discussed in relation to the isoantigenicity of spermatozoa, and to induced aspermatogenesis following the injection of testis or spermatozoa and adjuvant.

\section{INTRODUCTION}

It has been known for many years that guinea-pig spermatozoa are isoantigenic (see Voisin, Delaunay \& Barber, 1951; Freund, Lipton \& Thompson, 1953; Baum, Boughton, Mongar \& Schild. 1961). In contrast, spermatozoa of other species, such as the rabbit, do not elicit isoantibodies (Weil \& Finkler, 1959; Weil, 1960; Edwards, 1960 a and b). In the present work, we have utilized the fluorescent antibody technique to examine the site of reactions between serum and spermatozoa in several mammalian species.

* Present address: Pathology Department, The University and Western Infirmary, Glasgow W.1. $D^{* *}$ 


\section{MATERIAL AND METHODS}

SERA

Normal sera were obtained from adult and immature guinea-pigs and rabbits of both sexes, adult mice of both sexes, and adult men.

Two adult male and two adult female guinea-pigs were immunized by intramuscular injections of homologous epididymal spermatozoa in complete Freund's adjuvant. Two injections were given at weekly intervals, a total of $2 \times 10^{8}$ spermatozoa in $0.5 \mathrm{ml}$ adjuvant being injected into several different sites at each injection. One animal of each sex was bled from the heart after an interval of 23 days from the first injection, and the remaining two after an interval of 39 days. Two adult male and two adult female rabbits were immunized by 3 -weekly intramuscular injections of $2 \times 10^{8}$ epididymal rabbit spermatozoa in $1 \mathrm{ml}$ complete adjuvant. Samples of their blood were obtained 39 days after the initial immunization. Ten days later the animals were given an intravenous injection of $5 \times 10^{6}$ epididymal spermatozoa, repeated again after 2 days, and followed 3 days later by an intravenous injection of $5 \times 10^{7}$ spermatozoa. They were bled again 10 days later, i.e. 59 days after the initial injection.

All sera were stored at $-20^{\circ} \mathrm{C}$. Certain sera were inactivated for $30 \mathrm{~min}$ at $56^{\circ} \mathrm{C}$, and others were Seitz-filtered.

\section{SPERMATOZOA}

Epididymal spermatozoa from rabbits, guinea-pigs, rats, mice and hamsters, and ejaculated human spermatozoa, were suspended in $0.15 \mathrm{M}$-sodium chloride. Drops of the suspension were air-dried on slides, fixed by brief immersion in absolute alcohol, and air-dried again.

\section{FLUORESGENT ANTIBODY TEGHNIQUE}

The indirect staining method was used. Goat antibodies were prepared against $\gamma$-globulin of rabbit, while antibodies to guinea-pig, mouse and human $\gamma$ globulin were prepared in rabbits. The globulin fraction of the immune sera was prepared by salt fractionation and then conjugated with fluorescein, by the method of Riggs, Seiwald, Burckhalter, Downs \& Metcalf (1958). Nonspecific staining by the conjugate was prevented by absorption with acetonedried liver and testis powders and acetone-dried spermatozoa (Coons, 1956).

Serum was layered over the smears of spermatozoa for $30 \mathrm{~min}$ in a moist chamber, and then washed off in barbitone-buffered saline solution $(\mathrm{pH} 7 \cdot 2)$ with gentle agitation. Conjugate was layered on the smears for $30 \mathrm{~min}$ and then washed off for $10 \mathrm{~min}$. The smears were mounted in buffered glycerol $(\mathrm{pH} \mathrm{7 \cdot 2)}$ and examined by dark-field blue-violet/ultraviolet light.

The specificity of the reaction of the conjugated anti- $\gamma$-globulin antisera with their corresponding antigens was controlled in three ways:

(a) The conjugated anti- $\gamma$-globulin antisera failed to stain spermatozoa which had not been treated with serum.

(b) The specific staining property of the fluorescent anti- $\gamma$-globulin antisera 
on spermatozoa treated with serum was inhibited by pretreatment with the corresponding $\gamma$-globulin.

(c) Fluorescent anti-human serum albumin failed to stain spermatozoa treated with serum.

\section{EXAMINATION OF THE SPERMATOZOA}

Each smear was given a code number. The coded slides were then scored at random and independently by each author. The code numbers were classified after all slides had been scored.

\section{RESULTS}

REACTION BETWEEN NORMAL SERUM AND HOMOLOGOUS SPERMATOZOA

With normal adult rabbit serum, the acrosome of homologous spermatozoa stained brightly (Pl. 1, Fig. 1). This reaction occurred with every serum and sperm sample examined, the sera being obtained from adults of both sexes and the spermatozoa from several animals. Staining was barely detectable at serum dilutions of $1: 16$. With heat-inactivated sera or Seitz-filtered sera, staining was diminished though still easily detectable. The acrosome was usually uniformly stained, its outline being sharply demarcated, though in some of the smears the tip of the acrosome was stained more intensely. Dull staining of the posterior part of the head was seen occasionally but was of low intensity and not regularly reproducible. The mid-piece was not stained.

Normal sera from 3-weeks-old rabbits stained the acrosome moderately intensely, while serum from rabbits aged 3 days produced a dull staining only demonstrable with undiluted serum. When sera from these immature rabbits were heated or Seitz-filtered their staining capacity was lost. Normal adult guinea-pig sera regularly produced intense staining of the acrosome of homologous spermatozoa (Pl. 1, Fig. 2). The remainder of the head was weakly stained in a few smears, the mid-piece being unstained. The intensity of the acrosome staining was similar with sera from male and female animals, and was reduced but not removed by heat inactivation. Heat inactivation of serum from immature guinea-pigs greatly reduced but did not remove the acrosome stain.

Some, but not all of the sera obtained from adult male and female mice, and from normal men, produced low intensity staining of the homologous acrosome. The remainder of the spermatozoon was completely unstained.

REACTION BETWEEN NORMAL SERUM AND HETEROLOGOUS SPERMATOZOA

The results are summarized in Table 1 , where the intensity of the acrosome staining has been assessed arbitrarily on a six-point scale. The pattern of the heterologous reactions was determined mainly by the source of spermatozoa. In general, acrosome staining occurred more intensely in spermatozoa with large acrosomes such as the guinea-pig and rabbit, and weakly with spermatozoa from species with smaller acrosomes, e.g. mouse and rat (Pl. 1, Fig. 3). The reaction of normal serum with spermatozoa did not show any marked species specificity. 
REACTION BETWEEN HOMOLOGOUS SPERMATOZOA AND SERUM FROM ANIMALS IMMUNIZED WITH SPERMATOZOA

Sera from two guinea-pigs immunized 39 days beforehand regularly produced a delicate staining of the surface of homologous spermatozoal tails (Pl. 1, Fig. 4), and occasionally caused a very dull staining of the surface of the midpiece. All of this was in addition to the acrosome staining, which did not differ in intensity or titre from that produced by sera from normal unimmunized guinea-pigs. Staining of the surface of sperm tails was never encountered with sera from unimmunized guinea-pigs or from those autopsied 23 days after immunization. Immunization had evidently resulted in the formation of antibodies which reacted with components in the sperm tail.

The pattern of staining produced by sera from rabbits, which had been repeatedly injected with homologous spermatozoa, did not differ from that

TABLE 1

INTENSITY OF THE REACTION BETWEEN THE ACROSOMES OF SPERMATOZOA FROM SEVERAL SPECIES OF MAMMALS AND HOMOLOGOUS OR HETEROLOGOUS NORMAL SERUM

\begin{tabular}{|c|c|c|c|c|c|c|}
\hline \multirow{2}{*}{ Serum } & \multicolumn{6}{|c|}{ Spermatozoa } \\
\hline & Rabbit & Guinea-pig & Mouse & $R a t$ & Hamster & Man \\
\hline Rabbit & ++ & +++ & + & + & + & n.d. \\
\hline Guinea-pig & +++ & +++ & - & $?$ & \pm & n.d. \\
\hline Mouse & ++ & +++ & \pm & $?$ & + & n.d. \\
\hline Man & ++ & ++ & \pm & + & + & \pm \\
\hline
\end{tabular}

produced by normal rabbit serum in any respect. It appeared that we had been unsuccessful in eliciting antibodies against any part of the spermatozoon.

REAGTION BETWEEN HETEROLOGOUS SPERMATOZOA AND SERUM FROM GUINEAPIGS IMMUNIZED WITH HOMOLOGOUS SPERMATOZOA

Sera from guinea-pigs immunized with guinea-pig spermatozoa were tested against spermatozoa from the rabbit, mouse, rat and hamster. These sera produced acrosome staining of similar intensity to that found with sera from unimmunized animals. A very weak cross reaction appeared to be present against the sperm tail of hamsters, but not against tails of other species.

\section{DISCUSSION}

We consider that two distinct reactions of an immunological nature between serum and spermatozoa have been demonstrated in the present work. The 
reaction between serum and the acrosome occurred with serum from normal animals, whereas that between serum and the sperm tail occurred only after the immunization of guinea-pigs with homologous spermatozoa.

All of the species examined possessed the serum factor which reacted with the acrosome of homologous and heterologous spermatozoa. In general, the acrosome of guinea-pig and rabbit was intensely stained by sera from all species, whereas the acrosome of human, hamster, mouse and rat spermatozoa evoked a much weaker reaction. The serum factor resembled an antibody: it was heat-stable at $56^{\circ} \mathrm{C}$ though reduced in quantity by heating, absent or present in low titres in the sera of younger animals, and was a $\gamma$-globulin as judged by its antigenicity in the fluorescent antibody test. These observations have a striking parallel with results obtained in the complement fixation test using reaction mixtures of rabbit spermatozoa and serum (Edwards, 1960a and c). Sera from adult rabbits possessed a factor stable at $56^{\circ} \mathrm{C}$ which fixed complement in the presence of spermatozoa, could be removed by absorption with spermatozoa, was unchanged in titre after immunization of the donor with spermatozoa, and was absent from or present in low titres in the sera of young animals.

The reactive constituents of spermatozoa might also be identical in the two experiments. During complement fixation, the reagent was suspected to be hyaluronidase. Hyaluronidase is associated with the acrosome; clearly the fluorescence on the acrosome could be due to a system similar to that which fixes complement. The interaction between serum and the acrosome may also have other manifestations: fresh serum, which is rich in complement, immobilizes spermatozoa (Chang, 1947), and is well known to agglutinate spermatozoa by their heads. Examination of rabbit spermatozoa agglutinated by normal serum revealed that the head-to-head attachment was through the acrosome. The agglutination of spermatozoa by normal serum may thus be a further example of a specific interaction involving the acrosome.

The tail fluorescence of guinea-pig spermatozoa was almost certainly due to an induced isoantibody. It was absent with normal sera of all species examined, and occurred in guinea-pigs but not in rabbits challenged with homologous spermatozoa. Tail agglutination is considered to be specific for induced isoantibodies against spermatozoa, and the present observations appear to be a visual demonstration of the site of this agglutinating antigen. But sperm agglutination can be a misleading test: isoantibodies against seminal plasma caused tail agglutination of rabbit spermatozoa even though isoantibodies against the spermatozoa themselves could not be induced (Weil \& Finkler, 1959; Weil, 1960; Edwards, 1960b). The present work confirms the observations of these authors that isoantibodies cannot be invoked against rabbit spermatozoa. In this connexion, it is of interest that human isoantibodies against semen in sterile men are now considered to be specific for seminal plasma rather than spermatozoa (Weil, Kotsevalov \& Wilson, 1956; Rümke \& Hellinga, 1959), and that human testicular spermatozoa are evidently not antigenic in guinea-pigs (Weil \& Rosenburg, 1960). Spermatozoa of several species did not cross-react with isoantibodies against guinea-pig spermatozoa in the present experiment, though hamster spermatozoa apparently 
did do so. Using different techniques, previous workers have also shown that such isoantibodies did not cross-react with spermatozoa from mice, rats and boars (Voisin, Toullet \& Maurer, 1958; Baum et al., 1961). However, the fluorescent antibody technique may be too insensitive to detect such reactions, since Voisin et al. (1958) did find a cross-reaction between guinea-pig isoantibodies and rabbit spermatozoa using passive cutaneous anaphylaxis.

The present observations fail to support those of Baum and his co-workers (Baum, 1959; Baum et al., 1961) who claim that guinea-pig isoantibodies are produced against protamine in the sperm head. We consider that they have misinterpreted the acrosome fluorescence as being due to induced antibodies against protamine, and that they have overlooked the tail fluorescence. As far as we are aware, no isoantibodies specific to the sperm nucleus have been induced by challenge with spermatozoa. Holborrow \& Weir (1959) demonstrated that certain human patients possessed antibodies against nucleohistone in testicular and other cells, and that these sera did not react with spermatozoa.

It is tempting to speculate about the two specific systems demonstrated in the present work. Positive results with techniques such as passive cutaneous anaphylaxis, complement fixation, sperm agglutination, sperm immobilization, precipitins, haemagglutination, etc., which have been used by several workers to demonstrate isoantibodies after immunization with spermatozoa (e.g. Freund et al., 1953, 1954; Voisin et al., 1958; Baum et al., 1961), are probably due in part to induced antibodies against the sperm tail. The reaction between serum and the acrosome may be related to two other reactions involving hyaluronidase or the acrosome. First, a natural inhibitor of hyaluronidase exists in the serum of many mammals, and has been extensively studied (see the review by Mathews \& Dorfman, 1955). The physiological function of the inhibitor is unknown. It has been reported to be a mucoprotein and to segregate with the albumin, $a_{1-}$ and $a_{2}$-globulin fractions in electrophoresis, but in contrast to the serum factor in the present work, appears to be heat labile at $56^{\circ} \mathrm{C}$. A wide variety of species cross-reactions occur between hyaluronidase and the inhibitor. Secondly, hyaluronidase has recently been indicated as one of the antigens involved in the induction of aspermatogenesis in guineapigs after challenge with testis and adjuvant (Katsh, 1960b) though another non-protein antigen is also involved (Freund, Thompson \& Lipton, 1955). Testicular damage is induced only if secondary spermatocytes or later spermatogenic stages, which are known to possess idiosomal or acrosomal elements, are present in the challenging material (Freund et al., 1953; Katsh, 1960a). Waksman (1959a and b) found that lesions commenced most frequently in the epididymis, less often in the rete testis, and still less frequently in the body of the testis, though Katsh considers that the testicular reaction is an isoimmune-type reaction involving acrosomal material in secondary spermatocytes (see also Bishop, Narbaitz \& Lessof, 1961). Bishop (1961) has shown that adjuvant is unnecessary for inducing testicular damage provided that injections of testis are administered for a prolonged period.

The interaction between hyaluronidase and the inhibitor in serum, and the implication of the acrosome and possibly of hyaluronidase in the production of aspermatogenesis in guinea-pigs, may be in some way related to the staining 
of the acrosome described in the present work and to the fixation of complement by serum and spermatozoa. Indirect evidence supports this proposition. For example, since the acrosomes of several species are stained with guinea-pig serum, immunization with heterologous testis could be expected to impair spermatogenesis in guinea-pigs. Injections of rooster or monkey testis, or of human ejaculate do induce testicular destruction in guinea-pigs (Katsh \& Bishop, 1958), though injections of bull testis or hyaluronidase do not (Katsh, 1960b). Moreover, since serum from all species reacted with homologous acrosomes, some interference with spermatogenesis could presumably occur in many species after iso-immunization with spermatozoa. As far as we are aware, spermatogenesis is impaired in only two species besides guinea-pigs, namely rats (Freund et al., 1954) and rabbits (Katsh, 1958), though the impairment is less marked than in guinea-pigs iso-immunized with spermatozoa. A reaction between serum and the acrosome in vivo after iso-immunization with spermatozoa could lead to a general reaction against the acrosomes of spermatozoa present in the epididymis, and to a more specific response by spermatocytes in the testis. The seemingly contradictory observations of Katsh and Waksman might thus be resolved.

\section{AGKNOWLEDGMENTS}

One of us (J. S. B.) is indebted to the Medical Research Council for a Clinical Research Fellowship. We are most grateful to Dr J. H. Humphrey for advice and criticism, and to Miss Lorna Franklin and Miss Gillian Icke for their valuable technical assistance.

\section{REFERENCES}

BAUM, J. (1959) Reaction of guinea-pig spermatozoa with homologous antibody, Lancet, i, 810.

Baum, J., Boughton, B., Mongar, J. L. \& Schild, H. O. (1961) Autosensitization by sperm in guineapigs. Immunology, 4, 95.

Bishop, D. W. (1961) Aspermatogenesis induced by testicular antigen uncombined with adjuvant. Proc. Soc. exp. Biol., N.Y. 107, 116.

Bishop, D. W., Narbaitz, R. \& Lessof, M. (1961) Induced aspermatogenesis in adult guinea-pigs injected with testicular antigen and adjuvant in neonatal stages. Devel. Biol. 3, 444.

Chang, M. C. (1947) The effects of serum on spermatozoa. F. gen. Physiol. 30, 321.

Coons, A. H. (1956) Histochemistry with labelled antibody. Int. Rev. Cytol. 5, 1.

EDWARDs, R. G. (1960a) Complement-fixing activity of normal rabbit serum with rabbit spermatozoa and seminal plasma. F. Reprod. Fertil. 1, 268.

EDWARDS, R. G. (1960b) Antigenicity of rabbit semen, bull semen and egg yolk after intravaginal or intramuscular injections into female rabbits. F. Reprod. Fertil. 1, 385.

Edwards, R. G. (1960c) Isoantibodies against semen in rabbits. Symposium on Germ Cells and Development, Int. Inst. Embryol., Fondazione A. Baselli, Pallanza. p. 197.

Freund, J., Lipton, M. M. \& Thompson, G. E. (1953) Aspermatogenesis in guinea-pigs induced by testicular tissue and adjuvants. F. exp. Med. 97, 711 .

Freund, J., Lipton, M. M. \& Thompson, G. E. (1954) Impairment of spermatogenesis in the rat after cutaneous injection of testicular suspension with complete adjuvants. Proc. Soc. exp. Biol., N.Y. 87,408 .

FreUnd, J., Thomposn, G. E. \& Lipton, M. M. (1955) Aspermatogenesis, anaphylaxis, and cutaneous sensitization induced in the guinea-pig by homologous testicular extracts. $\mathcal{F}$. exp. Med. 101, 591.

Holborrow, E. J. \& WeIR, D. M. (1959) Histone: an essential component for the lupus erythematosus antinuclear reaction. Lancet, $\mathbf{i}, 809$. 
KATsh, S. (1958) Host-graft interrelationship and the effects of injections of organ homogenates and of cells upon the testes of experimental animals. Ann. N.Y. Acad. Sci. 73, 698.

KAtsh, S. (1960a) Localization and identification of antispermatogenic factor in guinea-pig testicles. Int. Arch. Allergy, 16, 241.

KATSH, S. (1960b) The anaphylactogenicity of testicular hyaluronidase and a species difference in testicular hyaluronidase demonstrated by isolated organ anaphylaxis. Int. Arch. Allergy, 17, 70.

Katsh, S. \& Bishop, D. W. (1958) The effect of homologous testicular and brain and heterologous testicular homogenates combined with adjuvant upon the testes of guinea-pigs. 7 . Embryol. exp. Morph. 6, 94.

Mathews, M. B. \& Dorfman, A. (1955) Inhibition of hyaluronidase. Physiol. Rev. 35, 381.

Rümke, P. \& Hellinga, G. (1959) Auto-antibodies against spermatozoa in sterile men. Amer. 7. clin. Path. 32, 357.

Riggs, J. L., Seiwald, R. J., Burckhalter, J. H., Downs, C. M. \& Metcalf, T. G. (1958) Isothiocyanate compounds as fluorescent labelling agents for immune serum. Amer. $\mathcal{J}$. Path. 34, 1081.

Voisin, G., Delaunay, A. \& Barber, M. (1951) Sur les lésions testiculaires provoquées chex le Cobaye par iso- et auto-sensibilization. Ann. Inst. Pasteur, 81, 48.

Voisin, G., Toullet, F. \& Maurer, P. (1958) The nature of tissular antigens with particular reference to auto-sensitization and transplantation immunity. Ann. N.Y. Acad. Sci. 73, 726.

WAksman, B. H. (1959a) A histological study of the auto-allergic testis lesion in the guinea-pig. $\mathcal{F}$. exp. Med. 109, 311.

Waksman, B. H. (1959b) Experimental allergic encephalomyelitis and the 'autoallergic' diseases. Int. Arch. Allergy, 14, Suppl. p. 1.

WEIL, A. J. (1960) Immunological differentiation of epididymal and seminal spermatozoa of the rabbit. Science, 131, 1040.

WeIL, A. J. \& Finkler, A. E. (1959) Isoantigenicity of rabbit semen. Proc. Soc. exp. Biol., N.Y. $102,624$.

Weil, A. J., Kotsevalov, O. \& Wirson, L. (1956) Antigens of human seminal plasma. Proc. Soc. exp. Biol., N.Y. 92, 606.

Weir, A. J. \& Rosenburg, J. M. (1960) Immunological differentiation of human testicular (spermatocoele) and seminal spermatozoa. Proc. Soc. exp. Biol., N.r. 105, 43.

\section{EXPLANATION OF PLATE 1}

FIG. 1. Staining of the acrosomes of rabbit spermatozoa with normal rabbit serum. The acrosome of one spermatozoa is evidently missing. The orange colour of the lower half of the rabbit sperm heads is not due to fluorescence. When seen on the microscope and recorded by colour photography the lower half of each head appears to be dark grey. $\times 810$.

FIG. 2. Staining of the acrosomes of guinea-pig spermatozoa with normal guinea-pig serum. The acrosome of one spermatozoa is evidently missing. $\times 810$.

FIG. 3. Staining of the acrosomes of mouse spermatozoa with normal rabbit serum. $\times 810$.

FIG. 4. Staining of the acrosome and tail of guinea-pig spermatozoa with serum from a guinea-pig immunized with homologous spermatozoa. The delicate staining of the tail faded rapidly when exposed to light under the microscope, and satisfactory colour photographs of only single spermatozoa were possible. $\times 810$. 
PI.TTY:
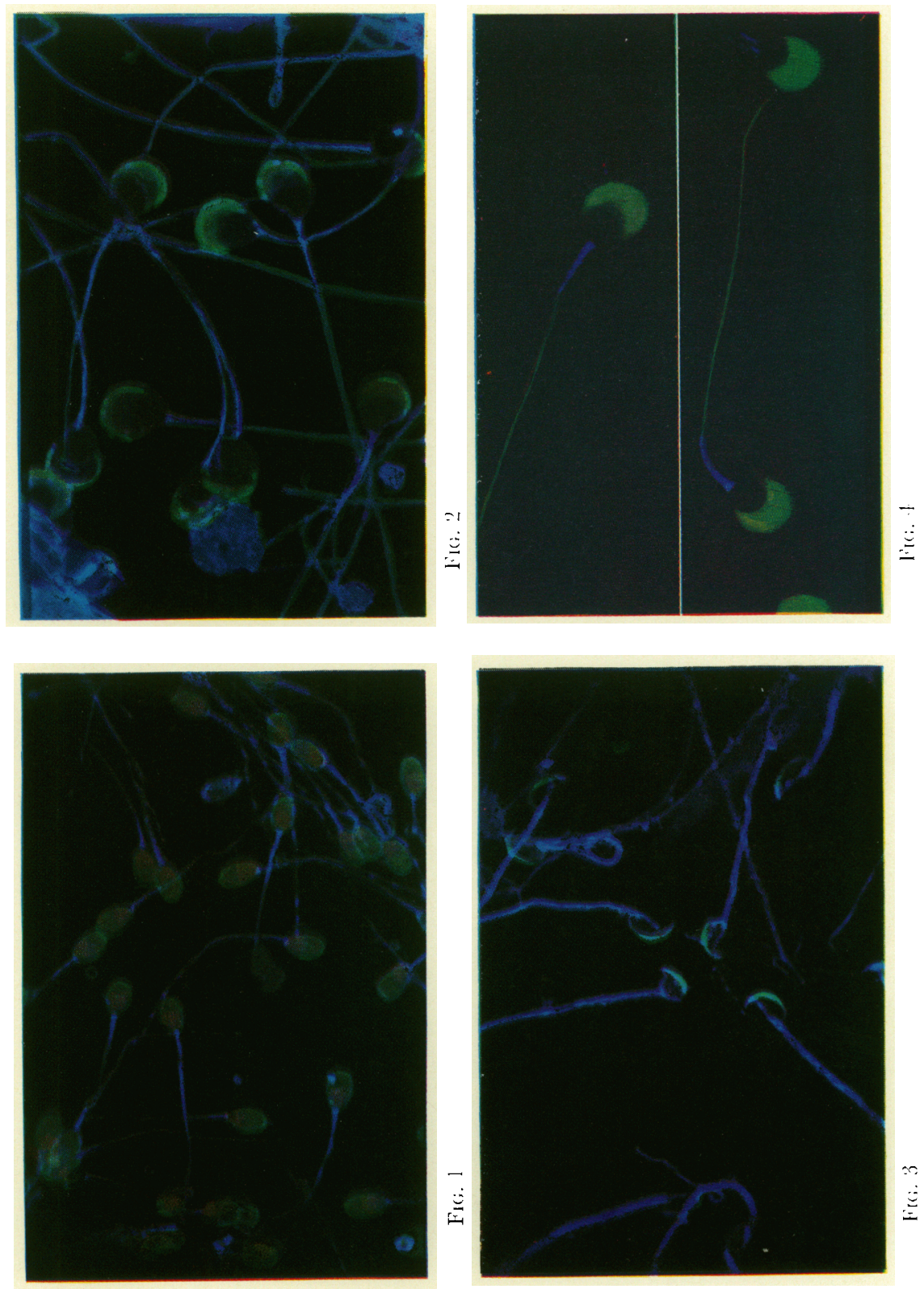

Fating 110 : 